\title{
Chemokines in Alzheimer's Disease: New Insights Into Prokineticins, Chemokine-Like Proteins
}

OPEN ACCESS

Edited by: Cesare Mancuso, Catholic University of the Sacred Heart, Italy

Reviewed by:

Rory R. Koenen,

Maastricht University, Netherlands

Raffaella Bonecchi,

Humanitas University,

Italy

*Correspondence:

Roberta Lattanzi

roberta.lattanzi@uniroma1.it

Specialty section: This article was submitted to Experimental Pharmacology and

Drug Discovery,

a section of the journal

Frontiers in Pharmacology

Received: 08 March 2019 Accepted: 15 May 2019

Published: 29 May 2019

Citation:

Zuena AR, Casolini P, Lattanzi R and Maftei $D$ (2019) Chemokines in

Alzheimer's Disease:

New Insights Into Prokineticins,

Chemokine-Like Proteins.

Front. Pharmacol. 10:622.

doi: 10.3389/fphar.2019.00622

\author{
Anna Rita Zuena ${ }^{1}$, Paola Casolini ${ }^{1}$, Roberta Lattanzi ${ }^{1 *}$ and Daniela Maftei ${ }^{2}$ \\ ${ }^{1}$ Department of Physiology and Pharmacology "Vittorio Erspamer," Sapienza University of Rome, Rome, Italy \\ ${ }^{2}$ Department of Biochemical Sciences "Alessandro Rossi Fanelli," Sapienza University of Rome, Rome, Italy
}

Alzheimer's disease is the most common neurodegenerative disorder characterized by the presence of $\beta$-amyloid aggregates deposited as senile plaques and by the presence of neurofibrillary tangles of tau protein. To date, there is a broad consensus on the idea that neuroinflammation is one of the most important component in Alzheimer's disease pathogenesis. Chemokines and their receptors, beside the well-known role in the immune system, are widely expressed in the nervous system, where they play a significant role in the neuroinflammatory processes. Prokineticins are a new family of chemokine-like molecules involved in numerous physiological and pathological processes including immunity, pain, inflammation, and neuroinflammation. Prokineticin 2 (PROK2) and its receptors PKR1 and PKR2 are widely expressed in the central nervous system in both neuronal and glial cells. In Alzheimer's disease, PROK2 sustains the neuroinflammatory condition and contributes to neurotoxicity, since its expression is strongly upregulated by amyloid- $\beta$ peptide and reversed by the PKR antagonist PC1. This review aims to summarize the current knowledge on the neurotoxic and/ or neuroprotective function of chemokines in Alzheimer's disease, focusing on the prokineticin system: it represents a new field of investigation that can stimulate the research of innovative pharmacotherapeutic strategies.

Keywords: Alzheimer's disease, chemokines, prokineticin receptors, Aß-peptide, prokineticins

\section{ALZHEIMER'S DISEASE}

Alzheimer's disease $(\mathrm{AD})$ is the most common progressive neurodegenerative disorder and is the most frequent cause of dementia, characterized by a progressive and irreversible mental decline with loss of cognitive skills and memory function. The histopathological hallmarks of $\mathrm{AD}$ are extracellular senile plaques that are aggregates of amyloid- $\beta(\mathrm{A} \beta)$ peptide, and intracellular aggregation of hyperphosphorylated tau protein that forms neurofibrillary tangles (Haass and Selkoe, 2007; Huang and Mucke, 2012). This aggregation causes a neurotoxic cascade, which, in turn, leads to neuronal degeneration and atrophy of the brain regions involved in memory and cognitive impairment (temporal and parietal lobe, pre-frontal cortex, and hippocampus), increasing, in this way, brain neuroinflammation (Raskin et al., 2015; Bronzuoli et al., 2016). It is well known, in fact, that neuronal dysfunction is not the solely cause of $\mathrm{AD}$ pathogenesis and progression. There are increasing evidences showing that microglia and astrocytes are implicated in the neuroinflammatory reactions that characterize this pathology. Microglia cells are the innate immune cells of the central nervous system (CNS) and are involved in regulating synaptic plasticity and remodelling neuronal circuits. Astrocytes 
are the most numerous glial cells in the brain, and they provide nutrients and structural support to neurons. Moreover, microglia and astrocytes are responsible for brain homeostasis, and they react to disease stressors by innate immune responses such as production and release of inflammatory mediators that aim to resolve pathological state. In persistent pathological conditions, such as neurodegenerative diseases, however, microglia as well as astrocytes change their physiological phenotype and, consequently, lose their helpful function. Several studies from post-mortem brains of $\mathrm{AD}$ patients and $\mathrm{AD}$ animal models have revealed a co-localization of reactive glial cells with senile plaques and neurofibrillary tangles (Parachikova et al., 2007; Hickman et al., 2008; Lopez-Gonzalez et al., 2015). In particular, the early recruitment of microglia around plaques seems beneficial in $\mathrm{AD}$ by promoting phagocytosis of $A \beta$. However, the excessive amount of $A \beta$ occurring with the disease progression overwhelms microglia, which loses its phagocytic capacity in favor of a pro-inflammatory role (Jay et al., 2015). It is known, in fact, that activation of microglia involves the release of several pro-inflammatory molecules (specifically IL-1 $\beta, \mathrm{TNF} \alpha$, and $\mathrm{C} 1 \mathrm{q}$ ) and induces the activation of astrocytes that consequently lose their neuroprotective activity (Liddelow et al., 2017). Astrocytes' neurotoxic phenotype is abundant in $\mathrm{AD}$ patients' brain. Therefore, in these conditions, microglia and astrocytes promote neuroinflammatory response, being responsible for the synthesis of different pro-inflammatory mediators including chemokines and mediators with chemokinelike function as defensins and macrophage migration inhibitory factor (MIF) (Casolini et al., 2002; Sudduth et al., 2013; Williams et al., 2013; Azizi et al., 2014; Guerriero et al., 2017; Chun et al., 2018).

This review aims to summarize the most current knowledge on role of chemokines in $\mathrm{AD}$, focusing on the prokineticins, chemokine-like molecules that have a role in the amyloid-induced neuronal damage (all the data shown below are summarized in Table 1).

\section{CHEMOKINES}

Chemokines are chemotactic cytokines originally identified as factors regulating immune cell migration to sites of inflammation (Luster, 1998). This family, also widely expressed in the CNS, exerts its functions through chemokine receptors that belong to the superfamily of G-protein-coupled receptors. Most chemokines bind to more than one receptor, and several distinct chemokines share common receptor (Rossi and Zlotnik, 2000). Chemokines can be classified into sub-families on the basis of the sequential position of the first two of the four cysteine residues: CXC, CC, CX3C, and C (Bachelerie et al., 2013). The main alteration in chemokines and receptors discriminating pathophysiological inflammatory conditions from physiological ones is their increased expression as demonstrated in plasma, cerebrospinal fluid (CSF), and brain tissue of patients with AD. Microglia, astrocytes, and neurons are believed to be the main source of chemokines and their receptors' production (Liu et al., 2014). In general, most of the chemokines and their receptors contribute to the neuroinflammatory component of $\mathrm{AD}$ by recruiting peripheral blood monocytes and promoting glial cell activation, even if emerging data hypothesize for some of them, a neuroprotective role.

CCL2 or monocyte chemoattractant protein 1 (MCP-1), mostly produced by glial cells, seems to have a detrimental role in $\mathrm{AD}$ pathogenesis, as its overexpression has been found in brain (Sokolova et al., 2009; Vukic et al., 2009), mature senile plaques, microglia, and microvessels of $\mathrm{AD}$ patients (Grammas and Ovase, 2001). Clinical data of AD patients have shown an increase of CCL2 both in CSF and in plasma (Westin et al., 2012; Zhang et al., 2013), and, according to several authors, it correlates with the disease progression and the cognitive decline (Galimberti et al., 2006a; Kimura et al., 2018; Lee et al., 2018). Conversely, other studies report no association between CCL2 plasma levels and AD (Kim et al., 2011; Porcellini et al., 2013). On the other hand, the deficit of CCR2 (CCL2 receptor) may aggravate the disease progression. In transgenic mouse models of AD (Tg2576 mice and APPswe/PSEN1), Ccr2 deficiency accelerates memory deficits and disease progression increasing the $A \beta$ soluble levels in the brain (El Khoury et al., 2007; Naert and Rivest, 2011). This could be due to an impaired macrophage recruitment, microglial accumulation, and $A \beta$ clearance, which seems to be CCR2 dependent.

CXCL8 (or interleukin 8) is produced in CNS by neurons, microglia, and astrocytes in response to proinflammatory signals. It has been found to be increased in serum, CSF, and brains of AD patients (Galimberti et al., 2006b; Ashutosh et al., 2011; Alsadany et al., 2013). Moreover, high levels of its receptors (CXCR2) have been reported in neuritic plaques of $\mathrm{AD}$ tissue, as well as in microglia and astrocytes (Xia et al., 1997; Flynn et al., 2003). Bakshi and collaborators have demonstrated in vitro that the knock-down or the pharmacological block of CXCR2 with the antagonist SB225002 induces an inhibition in A $\beta$ release, through inhibition of $\gamma$-secretase, while the activation of CXCR2, with the exogenous chemokines hrIL 8 and hrGRO- $\alpha$, leads to an increase in $\mathrm{A} \beta$. These data have been confirmed by the same authors in in vivo studies, in which $\mathrm{Cxcr} 2$ deficient mice show a reduction of $\mathrm{A} \beta$ that is associated to $\gamma$-secretase decrease (Bakshi et al., 2008, Bakshi et al., 2011). Furthermore, the intra-hippocampal $A \beta_{1-42}$ injection induces microglial chemotactic response that involves the hippocampal overexpression of CXCL8/CXCR2 in a timedependent manner (Ryu et al., 2015). The hippocampal $A \beta_{1-42}$ injection also causes an up-regulation of CXCR2 in peripheral T cells associated with an increased $\mathrm{T}$ cell entry in the brain. These effects are reduced by intraperitoneal injection with the CXCR2 antagonist SB332235 (Liu et al., 2010a).

CXCL10 (or IP-10). Clinical research in AD patients has demonstrated a positive correlation between the levels of CXCL10 in CSF and cognitive impairment (Galimberti et al., 2006b). CXCL10 is physiologically expressed in astrocytes and elevated in $\mathrm{AD}$ patients (Xia et al., 2000) and AD transgenic mice, where it co-localizes with A $\beta$ plaques (Duan et al., 2008; Zaheer et al., 2013). CXCL10 binds to CXCR3 receptor that plays a critical role in the generation of $\mathrm{AD}$ pathology: in a transgenic $\mathrm{AD}$ mouse model, CXCR3 deficiency significantly reduces $A \beta$ plaque formation and strongly diminishes $\mathrm{A} \beta$ peptide in brain tissue; this correlates with the improvement of the behavioral deficit (Krauthausen et al., 2015). 
TABLE 1 | Summary of the effects of chemokines and prokineticins in different cellular and animal models of AD and their expression in AD patients.

\begin{tabular}{|c|c|c|c|c|c|}
\hline Chemokines & Receptors & $\begin{array}{l}\text { Effect on cellular or } \\
\text { AD animal models }\end{array}$ & References & AD patients & References \\
\hline \multirow[t]{3}{*}{ CCL2 (MCP-1) } & CCR2 & $\begin{array}{l}\text { CCR2 deficient mice: } \\
\uparrow A \beta\end{array}$ & $\begin{array}{l}\text { El Khoury et al., } \\
\text { 2007; Naert and } \\
\text { Rivest, } 2011\end{array}$ & CCL2 $\uparrow$ in brain & $\begin{array}{l}\text { Grammas and Ovase, 2001; } \\
\text { Sokolova et al., 2009; Vukic } \\
\text { et al., } 2009\end{array}$ \\
\hline & & & & CCL2 $\uparrow$ in CSF & $\begin{array}{l}\text { Westin et al., 2012; Kimura } \\
\text { et al., } 2018\end{array}$ \\
\hline & & & & $\mathrm{CCL} 2 \uparrow$ in plasma & $\begin{array}{l}\text { Galimberti et al., 2006a; Zhang } \\
\text { et al., 2013; Lee et al., } 2018\end{array}$ \\
\hline \multirow[t]{3}{*}{ CCL5 (RANTES) } & CCR1 & CCR5 deficient mice: & Lee et al., 2009 & CCL5 $\uparrow$ in brain & Tripathy et al., 2010 \\
\hline & CCR3 & $\uparrow A \beta$ & & microvessels & \\
\hline & CCR5 & & & & \\
\hline \multirow[t]{8}{*}{ CXCL8 (IL-8) } & CXCR1 & In vitro & & CXCL8 $\uparrow$ in brain & Ashutosh et al., 2011 \\
\hline & CXCR2 & knock-down or & Bakshi et al., 2008 & CXCL8 $\uparrow$ in CSF & Galimberti et al., 2006b \\
\hline & & pharmacological block of & & CXCL8 $\uparrow$ in plasma & Alsadany et al., 2013 \\
\hline & & $\begin{array}{l}\text { CXCR2: } \downarrow A \beta ; \\
\text { activation of } \mathrm{CXCR} 2 \text { : }\end{array}$ & & $\begin{array}{l}\text { CXCR2 } \uparrow \text { in microglia } \\
\text { and astrocytes }\end{array}$ & Flynn et al., 2003 \\
\hline & & $\uparrow A \beta$ & & CXCR2 $\uparrow$ in neuritic & Xia et al., 1997 \\
\hline & & In vivo & & plaques & \\
\hline & & $\begin{array}{l}\text { CXCR2 deficient mice: } \\
\downarrow A \beta\end{array}$ & Bakshi et al., 2011 & & \\
\hline & & $\begin{array}{l}\text { Recruitment of } \\
\text { T-lymphocytes in the brain }\end{array}$ & Liu et al., 2010a & & \\
\hline CXCL10 (IP-10) & CXCR3 & $\begin{array}{l}\text { CXCR3 deficiency mice: } \\
\downarrow A \beta\end{array}$ & $\begin{array}{l}\text { Krauthausen et al., } \\
2015\end{array}$ & CXCL10 $\uparrow$ in brain & Xia et al., 2000 \\
\hline \multirow[t]{4}{*}{ CXCL12 (SDF-1a) } & CXCR4 & In vitro & & CXCL12 $\downarrow$ in plasma & Laske et al., 2008 \\
\hline & CXCR7 & CXCL12 prevents & Raman et al., 2011 & & \\
\hline & & dendritic regression & & CXCL12 $\downarrow$ in brain & Parachikova and Cotman, 2007 \\
\hline & & $\begin{array}{l}\text { and neuronal apoptosis } \\
\text { induced by } A \beta\end{array}$ & & CXCR4 $\uparrow$ in brain & $\begin{array}{l}\text { Parachikova and Cotman, } \\
\text { 2007; Weeraratna et al., } 2007\end{array}$ \\
\hline \multirow[t]{3}{*}{ CX3CL1 (Fractalkine) } & CX3CR1 & $\begin{array}{l}\text { CX3CR1 deficiency mice: } \\
\uparrow p-t a u\end{array}$ & $\begin{array}{l}\text { Bhaskar et al., 2010; } \\
\text { Bolós et al., 2017; }\end{array}$ & CX3CL1 $\uparrow$ in plasma & Kim et al., 2008 \\
\hline & & & Nash et al., 2013 & $\mathrm{CX} 3 \mathrm{CL} 1 \uparrow$ in brain & Strobel et al., 2015 \\
\hline & & $\begin{array}{l}\text { CX3CR1 deficiency mice: } \\
\downarrow A \beta\end{array}$ & $\begin{array}{l}\text { Lee et al., 2010; } \\
\text { Liu et al., 2010b }\end{array}$ & & \\
\hline \multirow[t]{6}{*}{ PROK2 } & PKR1 PKR2 & In vitro & & & \\
\hline & & Incubation of $\mathrm{CNs}$ with $\mathrm{A} \beta$ : & Severini et al., 2015; & & \\
\hline & & $\uparrow \mathrm{PROK} 2 / \mathrm{PKRs}$ & Caioli et al., 2017 & & \\
\hline & & In vivo & & & \\
\hline & & $\begin{array}{l}\text { Non-transgenic AD mice } \\
\text { model: }\end{array}$ & $\begin{array}{l}\text { Severini et al., 2015; } \\
\text { Lattanzi et al., } 2019\end{array}$ & & \\
\hline & & $\uparrow \mathrm{PROK} 2 / \mathrm{PKRs} / \mathrm{TM} 4-7$ & & & \\
\hline
\end{tabular}

CX3CL1 (also named fractalkine), unlike other chemokines, is produced as a transmembrane-anchored protein and exerts its functions as a membrane protein or as soluble isoforms. It is produced by neurons and astrocytes, whereas microglia constitutively express CX3CR1, its sole receptor (Mizuno et al., 2003). CX3CR1 is also partly expressed in astrocytes and neurons (Meucci et al., 2000; Cardona et al., 2006), suggesting that CX3CL1/CX3CR1 pathway plays a major role in neuron/ microglia communication and allows neurons to regulate microglia activation (Limatola and Ransohoff, 2014). Clinical studies suggest that CX3CL1/CX3CR1 may participate to the development of $\mathrm{AD}$ pathogenesis: serum fractalkine is elevated in patients with mild $\mathrm{AD}$, and its reduction is positively correlated with the cognitive decline (Kim et al., 2008). Moreover, an overexpression of CX3CL1 is present in the hippocampus of AD patients (Strobel et al., 2015). In AD animal models, different studies demonstrate a neuroprotective role of CX3CL1/ CX3CR1 axis in tau pathology by favoring an anti-inflammatory context. Transgenic mice lacking CX3CR1 show increased tau phosphorylation and aggregation associated with microglial activation and behavioral impairments (Bhaskar et al., 2010; Bolós et al., 2017). In a mouse model of AD, Nash and collaborators have confirmed these results: the overexpression of soluble fractalkine reduces tau pathology with a significant reduction of microglial activation and neuronal loss (Nash et al., 2013). Regarding the CX3CL1/CX3CR1 in A $\beta$ pathology, data seem to be divergent (Finneran and Nash, 2019). CX3CR1 deficiency in three different $\mathrm{AD}$ mouse models reduces $\beta$-amyloid deposition, enhancing A $\beta$ phagocytic ability by microglia (Lee et al., 2010; Liu et al., 2010b). Similarly, upregulation of CX3CR1 in the hippocampus of rats injected with $\mathrm{A} \beta_{1-40}$, induces microglial activation, synaptic dysfunction, and cognitive impairments (Wu et al., 2013). On the other hand, CX3CR1 deficiency in mice overexpressing human amyloid precursor protein (APP) exhibits enhanced tau pathology, microglial activation, expression of proinflammatory markers (IL-1 $\beta$, TNF- $\alpha$, and IL-6), neuronal death in the dentate gyrus, 
and worsened learning abilities (Cho et al., 2011). Moreover, in the same mouse model, a decrease in CX3CL1 has been shown in cerebral cortex and hippocampus (Duan et al., 2008).

CCL5 (also known as RANTES) and its receptors CCR5 are found on endothelial cells, glia, and neurons throughout the brain. The functional role of RANTES in AD is not completely clear. Indeed, different in vitro studies have shown that treatment of neuronal cultures with RANTES enhances neuronal survival (Tripathy et al., 2010) and protects against A $\beta$ toxicity (Bruno et al., 2000). Conversely, in vivo studies have reported that RANTES and CCR5 are increased in transgenic mice brain (Subramanian et al., 2010; Haskins et al., 2016) as well as in microvessels of AD human brain (Tripathy et al., 2010). CCR5 also binds other chemokines such as CCL3, whose role in $\mathrm{AD}$ is still not clear. However, mice lacking CCL3 or CCR5 exhibit a reduced glial activation and an improvement of spatial learning deficit induced by the intracerebroventricular (ICV) $A \beta_{1-40}$ injection (Passos et al., 2009). Moreover, the ICV administration of CCL3 in mice impairs synaptic transmission and spatial memory; these effects are reverted by a CCR5 antagonist (Maraviroc) (Marciniak et al., 2015). Furthermore, CCR5 deficiency results in enhanced longterm potentiation (LTP) and learning/memory performances, while neuronal CCR5 overexpression causes memory deficits (Zhou et al., 2016). In line with these findings, Lee and co-authors have demonstrated that CCR5 deficient mice have higher accumulation of $\mathrm{A} \beta$, associated with astrocyte activation in the brain, and an impairment of memory and learning functions (Lee et al., 2009).

The chemokine CXCL12 (SDF-1a), and its receptor CXCR4, are expressed and widely detected in the developing and adult CNS (Ma et al., 1998; Zou et al., 1998; Banisadr et al., 2002; Schönemeier et al., 2008). In addition to their role in neuroinflammation, they regulate neuronal excitability and synaptic transmission (Limatola et al., 2000) and modulate neuronal firing and neuron/glia communication (Bezzi et al., 2001). An upregulation of Cxcr4 gene and protein levels has been found in the brains of AD (Weeraratna et al., 2007). Furthermore, a decrease in plasma CXCL12 is reported in early AD patients and negatively correlated with CSF tau protein levels (Laske et al., 2008). In agreement with these results, Parachikova and Cotman (2007) show an increase of CXCR4 protein expression and a decrease of CXCL12 in the hippocampus of AD patients. However, the authors also demonstrate that transgenic AD mice, in which the mutation induces an overproduction of human APP, exhibit a reduction of CXCL12 and CXCR4 that correlates with deficits in different cognitive tasks. Moreover, chronic administration of a CXCR4 antagonist (AMD3100) results in impaired learning and memory in young non-transgenic mice, thus supporting the hypothesis that low levels of CXCL12/CXCR4 are linked to cognitive deficits (Lu et al., 2002). It has also been demonstrated that pre-treatment with CXCL12 inhibits the deleterious effect induced by the ICV injections of $A \beta$, suggesting that the beneficial effect of CXCL12/CXCR4 on memory and learning in AD could be linked to the prevention of dendritic regression and neuronal apoptosis induced by $\mathrm{A} \beta$ (Raman et al., 2011). In agreement with these data, a recent study demonstrates that CXCL12 mediates the neuroprotective and anti-amyloidogenic actions of human painless NGF (hNGFp) treatment in $5 \times$ FAD mice, transgenic mice that co-overexpress five familial AD mutant forms of human APP and presenilin 1 (Capsoni et al., 2017). Noteworthy, CXCL12 also binds CXCR7 that seems to be involved in the progression of various CNS pathologies including AD (Puchert et al., 2017).

\section{PROKINETICINS}

The amphibian Bv8 and mammalian prokineticin 2 (PROK2) are two secreted bioactive peptides that belong to the prokineticin (PK) family. Prokineticins are highly conserved across the species. They are characterized by the presence of a conserved N-terminal sequence AVITGA, 10 cysteine residues, that create five disulphidebridged motifs and a tryptophan residue in position 24 . A degree of similarity between prokineticin and defensins, a subclass of cationic antimicrobial peptides involved in innate immunity that, similarly to prokineticins, contain a high number of cysteine residues, was reported. However, their small size $(8 \mathrm{kDa})$, signaling mechanisms, receptor coupling ( $G$ protein-coupled receptors, GPCR), as well as chemotactic and immune-modulatory functions classify prokineticins as chemokines (Monnier and Samson, 2008; see also Negri and Ferrara, 2018).

Prokineticins activate two GPCR, prokineticin receptor 1 (PKR1) and 2 (PKR2), widely distributed in different organs and tissues as well as in CNS, in which PKR2 results more expressed. Both receptors are highly conserved sharing 85\% amino acid identity and diverging mainly in their $\mathrm{N}$-terminal region (Kaser et al., 2003). The PKRs are coupled to Gq, Gi, and Gs depending on the type of cellular localization and activate different intracellular signal pathways (for an explicative review, see Negri and Ferrara, 2018). It has also been reported that PKR2, at least in human neutrophils, undergoes dimerization (Marsango et al., 2011). Furthermore, in saccharomyces, the dimerization takes place from interactions between transmembrane domains TMs 4 and 5, with a specific role playing by TM5 on PKR2 function (Sposini et al., 2015).

PROK2 is abundantly expressed in CNS and associated with multiple physiological and pathological functions such as circadian rhythm, neurogenesis, angiogenesis, pain, inflammation, and neuroinflammation (Cheng et al., 2006; Zinni et al., 2017; Negri and Ferrara, 2018; Negri and Maftei, 2018).

The first evidence suggesting the potential role of PROK2/ PKRs in $\mathrm{AD}$ comes from in vitro and in vivo studies demonstrating their overexpression following $A \beta_{1-42}$ exposure. The incubation of primary cortical cell cultures (CNs) with $A \beta_{1-42}$ increases the $\mathrm{PROK} 2 / \mathrm{PKR} \mathrm{mRNA}$ and protein expression in a time-dependent way with a maximum increase at $48 \mathrm{~h}$. Immunofluorescence studies revealed that PKR1 only increases in neuronal cell body, while PROK2 and PKR2 increase both in neurons and in astrocytes (Severini et al., 2015; Caioli et al., 2017). The $A \beta_{1-42}$-induced PROK2 overexpression is strongly reduced by preincubation with PC1, a non-peptide PKR antagonist (Balboni et al., 2008; Congiu et al., 2014). Interestingly, $P C 1$ reverts the $A \beta_{1-42}$-induced neuronal death (in a concentration-dependent way), suggesting that reducing the activation of the PK system could be beneficial against $\mathrm{A} \beta_{1-42}$ induced neuronal toxicity. In support of these data, we found that the incubation of CNs with Bv8, the amphibian homologue of 
PROK2, induces neuronal apoptosis, comparable to the one exerted by $\mathrm{A} \beta$ peptide. It is also noteworthy that Bv8-induced neurotoxic effects are concentration-dependent, being achieved specifically at picomolar (and not at nanomolar) concentrations, and are blocked by pre-incubation with PC1. These low concentrations of Bv8, which induce the harmful effects, could be correlated with the small amount of PROK2, eventually released during A $\beta$ incubation. Along this line, a harmful effect of PROK2 at picomolar concentration is reported in cerebral ischemia (Cheng et al., 2012).

It is known that $A \beta_{1-42}$ induces a significant increase of the ionic current through the AMPA receptors (Parameshwaran et al., 2008; Wang et al., 2010). We have demonstrated that in neurons from $\mathrm{CNs}$, $\mathrm{A} \beta$ treatment affects the glutamatergic transmission through the involvement of the PK system (Caioli et al., 2017). Indeed, CNs incubated with Bv8, as well as with $\mathrm{A} \beta_{1-42}$, exhibit an alteration of glutamatergic transmission that results in increase in AMPA receptor ionic currents, measured both as evoked and as spontaneous, which are blocked by PC1. The up-modulation of AMPA ionic currents is not due to modifications of the GluR1 or GluR2 AMPA receptor subunit expression; rather, it appears to be mediated by modification in phosphorylation of AMPA subunits by the activation of protein kinase $\mathrm{C}$ (PKC) intracellular pathway. This is confirmed by the antagonist effect of $\mathrm{PKC}$ inhibitor (Go6983). Of note, PC1 also reduces neuronal death induced by kainite, thus exerting a protective action.

The involvement of the PK system in $\mathrm{AD}$ is also strongly supported by in vivo evidences. In the Tg2576 (TG) transgenic mouse model, PC1 exposure prevents LTP impairment in hippocampal slices, indicating that the pharmacological block of PKRs in TG neurons is sufficient to rescue the synaptic plasticity and to protect against the deleterious effect of PROK2. No changes are observed in age-matched wildtype controls, suggesting that PKR blockade does not affect synaptic plasticity in physiological conditions. In a nontransgenic animal model of $\mathrm{AD}$, induced by ICV injection of $\mathrm{A} \beta_{1-42}$, PROK2 and PKR mRNA expression is increased in both cortex and hippocampus (Severini et al., 2015). In addition, PKR2 mRNA levels in hippocampus are found to be increased not only in the early times ( $24 \mathrm{~h}$ after $\mathrm{A} \beta_{1-42}$ injection) but also in the later stage ( 14 days after $A \beta_{1-42}$ injection), indicating a significant role of $\mathrm{PK}$ system in the progression of pathology (Lattanzi et al., 2019).

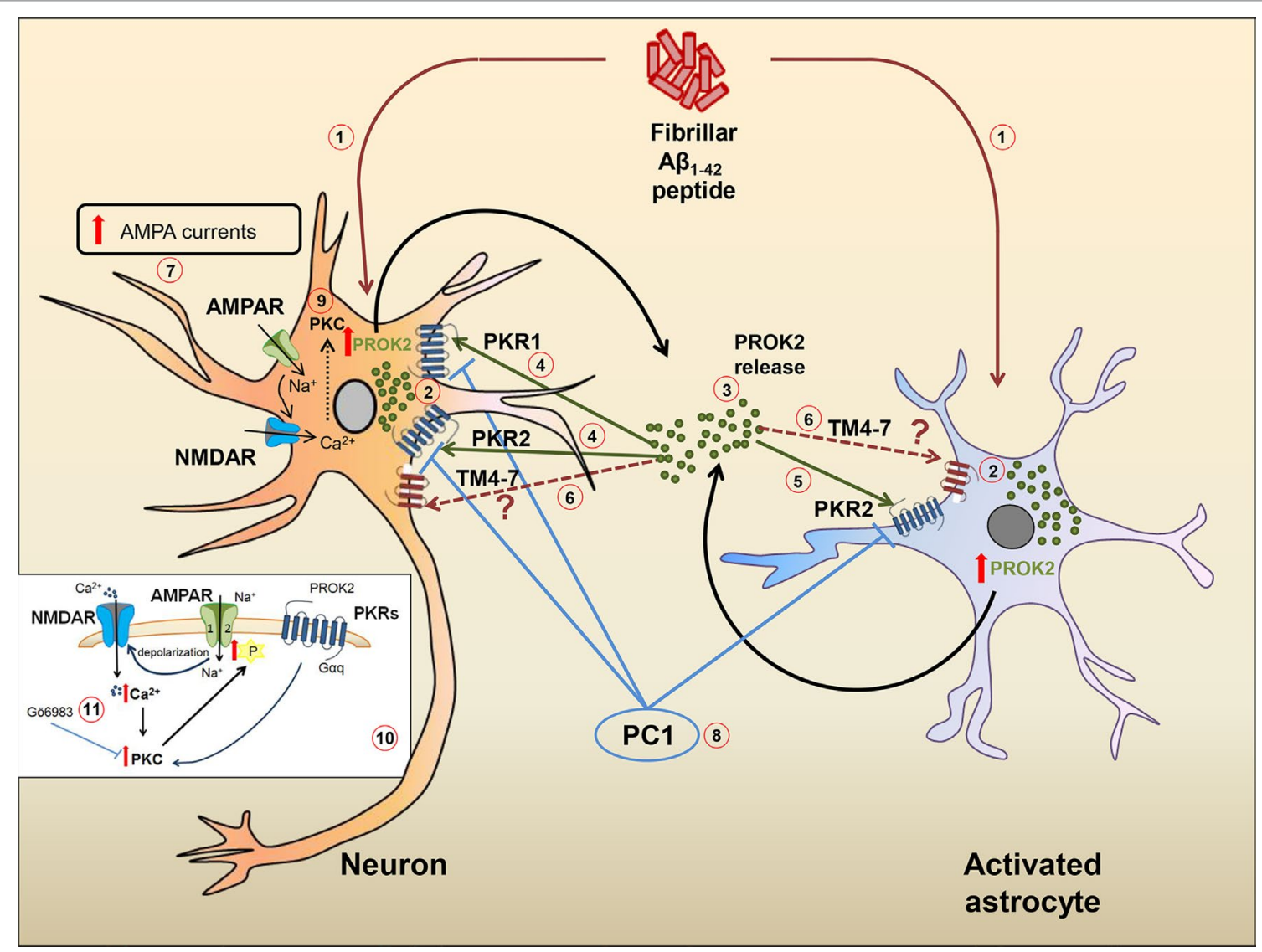

FIGURE 1 | Hypothetical role of the PK system in A 3 -mediated cell toxicity. Ab ${ }_{1-42}$ peptide (1) induces an increase of PROK2 in both neurons and astrocytes (2). Once released (3), PROK2 binds to PKR1 and PKR2 on neurons (4) and on PKR2 localized on astrocytes (5). PROK2 may also bind to the PKR2-truncated isoform (TM4-7) whose cell type localization and function is still unknown (6). At neuronal level, the increase of AMPA-receptor ionic currents induced by A (but also by Bv8) (7) seems to be mediated by the PK system, as it is blocked by the PKR antagonist PC1 (8). The up-modulation of AMPA ionic currents may be mediated by the activation of PKC intracellular pathways (9) [in detail illustrated in the small box (10)], as confirmed by the antagonistic effect of PKC inhibitor Go6983 (11). 
In $\mathrm{AD}$, the differential expression and the alternative splicing of genes notoriously involved in the pathology, such as APOE, APP, or tau, may contribute to the pathogenesis of the disease (Love et al., 2015). Alternative splicing of GPCR is a common mechanism that allows the formation of cell-specific isoforms with different biological activity in health and disease (Einstein et al., 2008; Wang et al., 2008).

In a recent paper, a PKR2 splice variant has been identified in rat hippocampus and called TM4-7 since the lack of the second exon gives rise to a receptor containing only four transmembrane domains. Interestingly, in the preclinical model of $\mathrm{AD}$ induced by ICV injection of $\mathrm{A} \beta$ in rat, the expression of TM4-7 receptor isoform is strongly up-regulated in the hippocampus and the expression ratio between the sliced form TM4-7 and the long form PKR2 increases with the progression of the disease, reaching maximum levels 35 days after $A \beta$ injection (Lattanzi et al., 2019). We can hypothesize that, as already observed in yeast (Lattanzi et al., 2019), also in the brain, TM4-7 may generate homodimer or heterodimer functional receptors with PKR2, so adding versatility and complexity to the already complex mechanisms of brain regulation induced by PROK2 and its receptors. A summary of the hypothetical role of PK system in $A \beta$-induced cell toxicity is shown in Figure 1.

\section{REFERENCES}

Alsadany, M. A., Shehata, H. H., Mohamad, M. I., and Mahfouz, R. G. (2013). Histone deacetylases enzyme, copper, and IL-8 levels in patients with Alzheimer's disease. Am. J. Alzheimers Dis. Other Demen. 28, 54-61. doi: 10.1177/1533317512467680

Ashutosh, Kou, W., Cotter, R., Borgmann, K., Wu, L., Persidsky, R., et al. (2011). CXCL8 protects human neurons from amyloid- $\beta$-induced neurotoxicity: relevance to Alzheimer's disease. Biochem. Biophys. Res. Commun. 412, 565571. doi: 10.1016/j.bbrc.2011.07.127

Azizi, G., Khannazer, N., and Mirshafiey, A. (2014). The potential role of chemokines in Alzheimer's disease pathogenesis. Am. J. Alzheimers Dis. Other Demen. 29, 415-425. doi: 10.1177/1533317513518651

Bachelerie, F., Ben-Baruch, A., Burkhardt, A. M., Combadiere, C., Farber, J. M., Graham, G. J., et al. (2013). International Union of Basic and Clinical Pharmacology. [corrected]. LXXXIX. Update on the extended family of chemokine receptors and introducing a new nomenclature for atypical chemokine receptors. Pharmacol. Rev. 66, 1-79. doi: 10.1124/pr.113.007724

Bakshi, P., Margenthaler, E., Laporte, V., Crawford, F., and Mullan, M. (2008). Novel role of CXCR2 in regulation of gamma-secretase activity. ACS Chem. Biol. 3, 777-789. doi: 10.1021/cb800167a

Bakshi, P., Margenthaler, E., Reed, J., Crawford, F., and Mullan, M. (2011). Depletion of CXCR2 inhibits $\gamma$-secretase activity and amyloid- $\beta$ production in a murine model of Alzheimer's disease. Cytokine 53, 163-169. doi: 10.1016/j.cyto.2010.10.008

Balboni, G., Lazzari, I., Trapella, C., Negri, L., Lattanzi, R., Giannini, E., et al. (2008). Triazine compounds as antagonists at Bv8-prokineticin receptors. J. Med. Chem. 51, 7635-7639. doi: 10.1021/jm800854e

Banisadr, G., Fontanges, P., Haour, F., Kitabgi, P., Rostène, W., Mélik Parsadaniantz, S., et al. (2002). Neuroanatomical distribution of CXCR4 in adult rat brain and its localization in cholinergic and dopaminergic neurons. Eur. J. Neurosci. 16, 1661-1671. doi: 10.1046/j.1460-9568.2002.02237.x

Bezzi, P., Domercq, M., Brambilla, L., Galli, R., Schols, D., De Clercq, E., et al. (2001). CXCR4-activated astrocyte glutamate release via TNFalpha: amplification by microglia triggers neurotoxicity. Nat. Neurosci. 4, 702-710. doi: 10.1038/89490

Bhaskar, K., Konerth, M., Kokiko-Cochran, O. N., Cardona, A., Ransohoff, R. M., and Lamb, B. T. (2010). Regulation of tau pathology by the microglial fractalkine receptor. Neuron 68, 19-31. doi: 10.1016/j.neuron.2010.08.023

\section{CONCLUSIONS}

The work summarized in the present review indicates that chemokines and their receptors are crucial neuroinflammatory actors for $\mathrm{AD}$ pathogenesis and/or progression. However, many gaps remain in the knowledge on the specific role of neuroinflammation in $\mathrm{AD}$, which impede the development of successful therapeutic strategies. Prokineticins represent a new class of chemokine-like proteins involved in $\mathrm{A} \beta$-induced toxicity and represent an innovative approach for the study of $\mathrm{AD}$ pathogenesis. Although in our laboratory many studies are still in progress, the success of the pharmacological blockade of PKRs (that reduces the $\mathrm{A} \beta$-induced neuronal death) leads us to hope for a future promising pharmacotherapeutic strategy of AD. This is particularly relevant considering that, to date, there are no drugs that block or slow down the progression of the disease.

\section{AUTHOR CONTRIBUTIONS}

ARZ and DM made literature search and wrote the first draft of the manuscript. PC and RL designed the aim of the review. DM drew the figure. All authors contributed to reading and approving the final version of the manuscript.

Bolós, M., Llorens-Martín, M., Perea, J. R., Jurado-Arjona, J., Rábano, A. Hernández, F., et al. (2017). Absence of CX3CR1 impairs the internalization of Tau by microglia. Mol. Neurodegener. 12, 59. doi: 10.1186/s13024-017-0200-1

Bronzuoli, M. R., Iacomino, A., Steardo, L., and Scuderi, C. (2016). Targeting neuroinflammation in Alzheimer's disease. J. Inflamm. Res. 9, 199-208. doi: 10.2147/JIR.S86958

Bruno, V., Copani, A., Besong, G., Scoto, G., and Nicoletti, F. (2000). Neuroprotective activity of chemokines against $\mathrm{N}$-methyl-D-aspartate or beta-amyloid-induced toxicity in culture. Eur. J. Pharmacol. 399, 117-121. doi: 10.1016/S00142999(00)00367-8

Caioli, S., Severini, C., Ciotti, T., Florenzano, F., Pimpinella, D., Petrocchi Passeri, P., et al. (2017). Prokineticin system modulation as a new target to counteract the amyloid beta toxicity induced by glutamatergic alterations in an in vitro model of Alzheimer's disease. Neuropharmacology 116, 82-97. doi: 10.1016/j. neuropharm.2016.12.012

Capsoni, S., Malerba, F., Carucci, N. M., Rizzi, C., Criscuolo, C., Origlia, N., et al. (2017). The chemokine CXCL12 mediates the anti-amyloidogenic action of painless human nerve growth factor. Brain 140, 201-217. doi: 10.1093/brain/ aww271

Cardona, A. E., Pioro, E. P., Sasse, M. E., Kostenko, V., Cardona, S. M., Dijkstra, I. M., et al. (2006). Control of microglial neurotoxicity by the fractalkine receptor. Nat. Neurosci. 9, 917-924. doi: 10.1038/nn1715

Casolini, P., Catalani, A., Zuena, A. R., and Angelucci, L. (2002). Inhibition of COX-2 reduces the age-dependent increase of hippocampal inflammatory markers, corticosterone secretion, and behavioral impairments in the rat. J. Neurosci. Res. 68, 337-343. doi: 10.1002/jnr.10192

Cheng, M. Y., Lee, A. G., Culbertson, C., Sun, G., Talati, R. K., Manley, N. C., et al. (2012). Prokineticin 2 is an endangering mediator of cerebral ischemic injury. Proc. Natl. Acad. Sci. U.S.A. 109, 5475-5480. doi: 10.1073/pnas.1113363109

Cheng, M. Y., Leslie, F. M., and Zhou, Q. Y. (2006). Expression of prokineticins and their receptors in the adult mouse brain. J. Comp. Neurol. 498, 796-809. doi: 10.1002/cne.21087

Cho, S. H., Sun, B., Zhou, Y., Kauppinen, T. M., Halabisky, B., Wes, P., et al. (2011). CX3CR1 protein signaling modulates microglial activation and protects against plaque-independent cognitive deficits in a mouse model of Alzheimer disease. J. Biol. Chem. 286, 32713-32722. doi: 10.1074/jbc.M111.254268 
Chun, H., Marriott, I., Lee, C. J., and Cho, H. (2018). Elucidating the interactive roles of glia in Alzheimer's disease using established and newly developed experimental models. Front. Neurol. 9, 797. doi: 10.3389/fneur.2018.00797

Congiu, C., Onnis, V., Deplano, A., Salvadori, S., Marconi, V., Maftei, D., et al. (2014). A new convenient synthetic method and preliminary pharmacological characterization of triazinediones as prokineticin receptor antagonists. Eur. J. Med. Chem. 81, 334-340. doi: 10.1016/j.ejmech.2014.05.030

Duan, R. S., Yang, X., Chen, Z. G., Lu, M. O., Morris, C., Winblad, B., et al. (2008). Decreased fractalkine and increased IP-10 expression in aged brain of APP(swe) transgenic mice. Neurochem. Res. 33, 1085-1089. doi: 10.1007/s11064-007-9554-Z

Einstein, R., Jordan, H., Zhou, W., Brenner, M., Moses, E. G., and Liggett, S. B. (2008). Alternative splicing of the G protein-coupled receptor superfamily in human airway smooth muscle diversifies the complement of receptors. Proc. Natl. Acad. Sci. U.S.A. 105, 5230-5235. doi: 10.1073/pnas.0801319105

El Khoury, J., Toft, M., Hickman, S. E., Means, T. K., Terada, K., Geula, C., et al. (2007). Ccr2 deficiency impairs microglial accumulation and accelerates progression of Alzheimer-like disease. Nat. Med. 13, 432-438. doi: 10.1038/nm1555

Finneran, D. J., and Nash, K. R. (2019). Neuroinflammation and fractalkine signaling in Alzheimer's disease. J. Neuroinflammation 16, 30. doi: 10.1186/ s12974-019-1412-9

Flynn, G., Maru, S., Loughlin, J., Romero, I. A., and Male, D. (2003). Regulation of chemokine receptor expression in human microglia and astrocytes. J. Neuroimmunol. 136, 84-93. doi: 10.1016/S0165-5728(03)00009-2

Galimberti, D., Fenoglio, C., Lovati, C., Venturelli, E., Guidi, I., Corrà, B., et al. (2006a). Serum MCP-1 levels are increased in mild cognitive impairment and mild Alzheimer's disease. Neurobiol. Aging 27, 1763-1768. doi: 10.1016/j. neurobiolaging.2005.10.007

Galimberti, D., Schoonenboom, N., Scheltens, P., Fenoglio, C., Bouwman, F., Venturelli, E., et al. (2006b). Intrathecal chemokine synthesis in mild cognitive impairment and Alzheimer disease. Arch. Neurol. 63, 538-543. doi: 10.1001/archneur.63.4.538

Grammas, P., and Ovase, R. (2001). Inflammatory factors are elevated in brain microvessels in Alzheimer's disease. Neurobiol. Aging 22, 837-842. doi: 10.1016/S0197-4580(01)00276-7

Guerriero, F., Sgarlata, C., Francis, M., Maurizi, N., Faragli, A., Perna, S., et al. (2017). Neuroinflammation, immune system and Alzheimer disease: searching for the missing link. Aging Clin. Exp. Res. 29, 821-831. doi: 10.1007/s40520-016-0637-z

Haass, C., and Selkoe, D. J. (2007). Soluble protein oligomers in neurodegeneration: lessons from the Alzheimer's amyloid beta-peptide. Nat. Rev. Mol. Cell Biol. 8, 101-112. doi: 10.1038/nrm2101

Haskins, M., Jones, T. E., Lu, Q., and Bareiss, S. K. (2016). Early alterations in blood and brain RANTES and MCP-1 expression and the effect of exercise frequency in the 3xTg-AD mouse model of Alzheimer's disease. Neurosci. Lett. 610, 165170. doi: 10.1016/j.neulet.2015.11.002

Hickman, S. E., Allison, E. K., and El Khoury, J. (2008). Microglial dysfunction and defective beta-amyloid clearance pathways in aging Alzheimer's disease mice. J. Neurosci. 28, 8354-8360. doi: 10.1523/JNEUROSCI.0616-08.2008

Huang, Y., and Mucke, L. (2012). Alzheimer mechanisms and therapeutic strategies. Cell 148, 1204-1222. doi: 10.1016/j.cell.2012.02.040

Jay, T. R., Miller, C. M., Cheng, P. J., Graham, L. C., Bemiller, S., Broihier, M. L., et al. (2015). TREM2 deficiency eliminates TREM2+ inflammatory macrophages and ameliorates pathology in Alzheimer's disease mouse models. J. Exp. Med. 212, 287-295. doi: 10.1084/jem.20142322

Kaser, A., Winklmayr, M., Lepperdinger, G., and Kreil, G. (2003). The AVIT protein family. Secreted cysteine-rich vertebrate proteins with diverse functions. EMBO Rep. 4, 469-473. doi: 10.1038/sj.embor.embor830

Kim, S. M., Song, J., Kim, S., Han, C., Park, M. H., Koh, Y., et al. (2011). Identification of peripheral inflammatory markers between normal control and Alzheimer's disease. BMC Neurol. 11, 51. doi: 10.1186/1471-2377-11-51

Kim, T. S., Lim, H. K., Lee, J. Y., Kim, D. J., Park, S., Lee, C., et al. (2008). Changes in the levels of plasma soluble fractalkine in patients with mild cognitive impairment and Alzheimer's disease. Neurosci. Lett. 436, 196-200. doi: 10.1016/j.neulet.2008.03.019

Kimura, A., Yoshikura, N., Hayashi, Y., and Inuzuka, T. (2018). Cerebrospinal fluid C-C motif chemokine ligand 2 correlates with brain atrophy and cognitive impairment in Alzheimer's disease. J. Alzheimers Dis. 61, 581-588. doi: 10.3233/JAD-170519

Krauthausen, M., Kummer, M. P., Zimmermann, J., Reyes-Irisarri, E., Terwel, D., Bulic, B., et al. (2015). CXCR3 promotes plaque formation and behavioral deficits in an Alzheimer's disease model. J. Clin. Invest. 125, 365-378. doi: 10.1172/JCI66771

Laske, C., Stellos, K., Stransky, E., Seizer, P., Akcay, O., Eschweiler, G. W., et al. (2008). Decreased plasma and cerebrospinal fluid levels of stem cell factor in patients with early Alzheimer's disease. J. Alzheimers Dis. 15, 451-460. doi: 10.3233/JAD-2008-15311

Lattanzi, R., Maftei, D., Fullone, M. R., and Miele, R. (2019). Identification and characterization of Prokineticin receptor 2 splicing variant and its modulation in an animal model of Alzheimer's disease. Neuropeptides 73, 49-56. doi: 10.1016/j.npep.2018.11.006

Lee, S., Varvel, N. H., Konerth, M. E., Xu, G., Cardona, A. E., Ransohoff, R. M., et al. (2010). CX3CR1 deficiency alters microglial activation and reduces betaamyloid deposition in two Alzheimer's disease mouse models. Am. J. Pathol. 177, 2549-2562. doi: 10.2353/ajpath.2010.100265

Lee, W. J., Liao, Y. C., Wang, Y. F., Lin, I. F., Wang, S. J., and Fuh, J. L. (2018). Plasma MCP-1 and cognitive decline in patients with Alzheimer's disease and mild cognitive impairment: a Two-year Follow-up Study. Sci. Rep. 8, 1280. doi: 10.1038/s41598-018-19807-y

Lee, Y. K., Kwak, D. H., Oh, K. W., Nam, S. Y., Lee, B. J., Yun, Y. W., et al. (2009). CCR5 deficiency induces astrocyte activation, Abeta deposit and impaired memory function. Neurobiol. Learn. Mem. 92, 356-363. doi: 10.1016/j.nlm.2009.04.003

Liddelow, S. A., Guttenplan, K. A., Clarke, L. E., Bennett, F. C., Bohlen, C. J., Schirmer, L., et al. (2017). Neurotoxic reactive astrocytes are induced by activated microglia. Nature 541, 481-487. doi: 10.1038/nature21029

Limatola, C., and Ransohoff, R. M. (2014). Modulating neurotoxicity through CX3CL1/ CX3CR1 signaling. Front. Cell. Neurosci. 8, 229. doi: 10.3389/fncel.2014.00229

Limatola, C., Giovannelli, A., Maggi, L., Ragozzino, D., Castellani, L., Ciotti, M. T., et al. (2000). SDF-1alpha-mediated modulation of synaptic transmission in rat cerebellum. Eur. J. Neurosci. 12, 2497-2504. doi: 10.1046/j.1460-9568.2000.00139.x

Liu, C., Cui, G., Zhu, M., Kang, X., and Guo, H. (2014). Neuroinflammation in Alzheimer's disease: chemokines produced by astrocytes and chemokine receptors. Int. J. Clin. Exp. Pathol. 7, 8342-8355.

Liu, Y. J., Guo, D. W., Tian, L., Shang, D. S., Zhao, W. D., Li, B., et al. (2010a). Peripheral T cells derived from Alzheimer's disease patients overexpress CXCR2 contributing to its transendothelial migration, which is microglial TNF-alpha-dependent. Neurobiol. Aging 31, 175-188. doi: 10.1016/j.neurobiolaging.2008.03.024

Liu, Z., Condello, C., Schain, A., Harb, R., and Grutzendler, J. (2010b). CX3CR1 in microglia regulates brain amyloid deposition through selective protofibrillar amyloid- $\beta$ phagocytosis. J. Neurosci. 30, 17091-17101. doi: 10.1523/ JNEUROSCI.4403-10.2010

López-González, I., Schlüter, A., Aso, E., Garcia-Esparcia, P., Ansoleaga, B., LLorens, F., et al. (2015). Neuroinflammatory signals in Alzheimer disease and APP/PS1 transgenic mice: correlations with plaques, tangles, and oligomeric species. J. Neuropathol. Exp. Neurol. 74, 319-344. doi: 10.1097/NEN.0000000000000176

Love, J. E., Hayden, E. J., and Rohn, T. T. (2015). Alternative splicing in Alzheimer's disease. J. Parkinsons Dis. Alzheimers Dis. 2 (2), 6. doi: 10.13188/2376-922X.1000010

Lu, M., Grove, E. A., and Miller, R. J. (2002). Abnormal development of the hippocampal dentate gyrus in mice lacking the CXCR4 chemokine receptor. Proc. Natl. Acad. Sci. U.S.A. 99, 7090-7095. doi: 10.1073/pnas.092013799

Luster, A. D. (1998). Chemokines - chemotactic cytokines that mediate inflammation. N. Engl. J. Med. 338, 436-445. doi: 10.1056/NEJM199802123380706

Ma, Q., Jones, D., Borghesani, P. R., Segal, R. A., Nagasawa, T., Kishimoto, T., et al. (1998). Impaired B-lymphopoiesis, myelopoiesis, and derailed cerebellar neuron migration in CXCR4- and SDF-1-deficient mice. Proc. Natl. Acad. Sci. U.S.A. 95, 9448-9453. doi: 10.1073/pnas.95.16.9448

Marciniak, E., Faivre, E., Dutar, P., Alves Pires, C., Demeyer, D., Caillierez, R., et al. (2015). The Chemokine MIP-1a/CCL3 impairs mouse hippocampal synaptic transmission, plasticity and memory. Sci. Rep. 5, 15862. doi: 10.1038/srep15862

Marsango, S., Bonaccorsi di Patti, M. C., Barra, D., and Miele, R. (2011). Evidence that prokineticin receptor 2 exists as a dimer in vivo. Cell. Mol. Life Sci. 68, 2919-2929. doi: 10.1007/s00018-010-0601-6

Meucci, O., Fatatis, A., Simen, A. A., and Miller, R. J. (2000). Expression of CX3CR1 chemokine receptors on neurons and their role in neuronal survival. Proc. Natl. Acad. Sci. U.S.A. 97, 8075-8080. doi: 10.1073/pnas.090017497

Mizuno, T., Kawanokuchi, J., Numata, K., and Suzumura, A. (2003). Production and neuroprotective functions of fractalkine in the central nervous system. Brain Res. 979, 65-70. doi: 10.1016/S0006-8993(03)02867-1

Monnier, J., and Samson, M. (2008). Cytokine properties of prokineticins. FEBS J. 275, 4014-4021. doi: 10.1111/j.1742-4658.2008.06559.x

Naert, G., and Rivest, S. (2011). CC chemokine receptor 2 deficiency aggravates cognitive impairments and amyloid pathology in a transgenic mouse model of Alzheimer's disease. J. Neurosci. 31, 6208-6220. doi: 10.1523/ JNEUROSCI.0299-11.2011 
Nash, K. R., Lee, D. C., Hunt, J.B. Jr, Morganti, J. M., Selenica, M. L., Moran, P., et al. (2013). Fractalkine overexpression suppresses tau pathology in a mouse model of tauopathy. Neurobiol. Aging 34, 1540-1548. doi: 10.1016/j.neurobiolaging.2012.12.011

Negri, L., and Ferrara, N. (2018). The prokineticins: neuromodulators and mediators of inflammation and myeloid cell-dependent angiogenesis. Physiol. Rev. 98, 10551082. doi: 10.1152/physrev.00012.2017

Negri, L., and Maftei, D. (2018). Targeting the prokineticin system to control chronic pain and inflammation. Curr. Med. Chem. 25, 3883-3894. doi: 10.2174 /0929867324666170713102514

Parachikova, A., and Cotman, C. W. (2007). Reduced CXCL12/CXCR4 results in impaired learning and is downregulated in a mouse model of Alzheimer disease. Neurobiol. Dis. 28, 143-153. doi: 10.1016/j.neurobiolaging.2006.08.014

Parachikova, A., Agadjanyan, M. G., Cribbs, D. H., Blurton-Jones, M., Perreau, V., Rogers, J., et al. (2007). Inflammatory changes parallel the early stages of Alzheimer disease. Neurobiol. Aging 28, 1821-1833. doi: 10.1016/j. neurobiolaging.2006.08.014

Parameshwaran, K., Dhanasekaran, M., and Suppiramaniam, V. (2008). Amyloid beta peptides and glutamatergic synaptic dysregulation. Exp. Neurol. 210, 7-13. doi: 10.1016/j.expneurol.2007.10.008

Passos, G. F., Figueiredo, C. P., Prediger, R. D., Pandolfo, P., Duarte, F. S., Medeiros, R., et al. (2009). Role of the macrophage inflammatory protein-1alpha/CC chemokine receptor 5 signaling pathway in the neuroinflammatory response and cognitive deficits induced by beta-amyloid peptide. Am. J. Pathol. 175, 1586-1597. doi: 10.2353/ajpath.2009.081113

Porcellini, E., Ianni, M., Carbone, I., Franceschi, M., and Licastro, F. (2013). Monocyte chemoattractant protein-1 promoter polymorphism and plasma levels in Alzheimer's disease. Immun. Ageing 10, 6. doi: 10.1186/1742-4933-10-6

Puchert, M., Pelkner, F., Stein, G., Angelov, D. N., Boltze, J., Wagner, D. C., et al. (2017). Astrocytic expression of the CXCL12 receptor, CXCR7/ACKR3 is a hallmark of the diseased, but not developing CNS. Mol. Cell. Neurosci. 85, 105-118. doi: 10.1016/j. mcn.2017.09.001

Raman, D., Milatovic, S. Z., Milatovic, D., Splittgerber, R., Fan, G. H., and Richmond, A. (2011). Chemokines, macrophage inflammatory protein-2 and stromal cell-derived factor-1 $\alpha$, suppress amyloid $\beta$-induced neurotoxicity. Toxicol. Appl. Pharmacol. 256, 300-313. doi: 10.1016/j.taap.2011.06.006

Raskin, J., Cummings, J., Hardy, J., Schuh, K., and Dean, R. A. (2015). Neurobiology of Alzheimer's disease: integrated molecular, physiological, anatomical, biomarker, and cognitive dimensions. Curr. Alzheimer Res. 12, 712-722. doi: $10.2174 / 1567205012666150701103107$

Rossi, D., and Zlotnik, A. (2000). The biology of chemokines and their receptors. Annu. Rev. Immunol. 18, 217-242. doi: 10.1146/annurev.immunol.18.1.217

Ryu, J. K., Cho, T., Choi, H. B., Jantaratnotai, N., and McLarnon, J. G. (2015). Pharmacological antagonism of interleukin-8 receptor CXCR2 inhibits inflammatory reactivity and is neuroprotective in an animal model of Alzheimer's disease. J. Neuroinflammation 12, 144. doi: 10.1186/s12974-015-0339-Z

Schönemeier, B., Kolodziej, A., Schulz, S., Jacobs, S., Hoellt, V., and Stumm, R. (2008). Regional and cellular localization of the CXCl12/SDF-1 chemokine receptor CXCR7 in the developing and adult rat brain. J. Comp. Neurol. 510, 207-220. doi: 10.1002/cne.21780

Severini, C., Lattanzi, R., Maftei, D., Marconi, V., Ciotti, M. T., Petrocchi Passeri, P., et al. (2015). Bv8/prokineticin 2 is involved in A $\beta$-induced neurotoxicity. Sci. Rep. 5, 15301. doi: 10.1038/srep 15301

Sokolova, A., Hill, M. D., Rahimi, F., Warden, L. A., Halliday, G. M., and Shepherd, C. E. (2009). Monocyte chemoattractant protein-1 plays a dominant role in the chronic inflammation observed in Alzheimer's disease. Brain Pathol. 19, 392-398. doi: 10.1111/j.1750-3639.2008.00188.x

Sposini, S., Caltabiano, G., Hanyaloglu, A. C., and Miele, R. (2015). Identification of transmembrane domains that regulate spatial arrangements and activity of prokineticin receptor 2 dimers. Mol. Cell. Endocrinol. 399, 362-372. doi: 10.1016/j.mce.2014.10.024

Strobel, S., Grünblatt, E., Riederer, P., Heinsen, H., Arzberger, T., Al-Sarraj, S., et al. (2015). Changes in the expression of genes related to neuroinflammation over the course of sporadic Alzheimer's disease progression: CX3CL1, TREM2, and PPAR $\gamma$. J. Neural. Transm. 122, 1069-1076. doi: 10.1007/s00702-015-1369-5

Subramanian, S., Ayala, P., Wadsworth, T. L., Harris, C. J., Vandenbark, A. A., Quinn, J. F., et al. (2010). CCR6: a biomarker for Alzheimer's-like disease in a triple transgenic mouse model. J. Alzheimers Dis. 22, 619-629. doi: 10.3233/JAD-2010-100852
Sudduth, T. L., Schmitt, F. A., Nelson, P. T., and Wilcock, D. M. (2013) Neuroinflammatory phenotype in early Alzheimer's disease. Neurobiol. Aging 34, 1051-1059. doi: 10.1016/j.neurobiolaging.2012.09.012

Tripathy, D., Thirumangalakudi, L., and Grammas, P. (2010). RANTES upregulation in the Alzheimer's disease brain: a possible neuroprotective role. Neurobiol. Aging 31, 8-16. doi: 10.1016/j.neurobiolaging.2008.03.009

Vukic, V., Callaghan, D., Walker, D., Lue, L. F., Liu, Q. Y., Couraud, P. O., et al. (2009). Expression of inflammatory genes induced by beta-amyloid peptides in human brain endothelial cells and in Alzheimer's brain is mediated by the JNK-AP1 signaling pathway. Neurobiol. Dis. 34, 95-106. doi: 10.1016/j.nbd.2008.12.007

Wang, D., Govindaiah, G., Liu, R., De Arcangelis, V., Cox, C. L., and Xiang, Y. K. (2010). Binding of amyloid beta peptide to beta2 adrenergic receptor induces PKA-dependent AMPA receptor hyperactivity. FASEB J. 24, 3511-3521. doi: 10.1096/fj.10-156661

Wang, E. T., Sandberg, R., Luo, S., Khrebtukova, I., Zhang, L., Mayr, C., et al. (2008). Alternative isoform regulation in human tissue transcriptomes. Nature 456, 470476. doi: 10.1038/nature07509

Weeraratna, A. T., Kalehua, A., Deleon, I., Bertak, D., Maher, G., Wade, M. S., et al. (2007). Alterations in immunological and neurological gene expression patterns in Alzheimer's disease tissues. Exp. Cell Res. 313, 450-461. doi: 10.1016/j.yexcr. 2006.10.028

Westin, K., Buchhave, P., Nielsen, H., Minthon, L., Janciauskiene, S., and Hansson, O. (2012). CCL2 is associated with a faster rate of cognitive decline during early stages of Alzheimer's disease. PLoS One 7, e30525. doi: 10.1371/journal.pone.0030525

Williams, W. M., Torres, S., Siedlak, S. L., Castellani, R. J., Perry, G., Smith, M. A., et al. (2013). Antimicrobial peptide $\beta$-defensin-1 expression is upregulated in Alzheimer's brain. J. Neuroinflammation 10, 127. doi: 10.1186/1742-2094-10-127

Wu, J., Bie, B., Yang, H., Xu, J. J., Brown, D. L., and Naguib, M. (2013). Suppression of central chemokine fractalkine receptor signaling alleviates amyloidinduced memory deficiency. Neurobiol. Aging 34, 2843-2852. doi: 10.1016/j. neurobiolaging.2013.06.003

Xia, M., Qin, S., McNamara, M., Mackay, C., and Hyman, B. T. (1997). Interleukin-8 receptor B immunoreactivity in brain and neuritic plaques of Alzheimer's disease. Am. J. Pathol. 150, 1267-1274.

Xia, M. Q., Bacskai, B. J., Knowles, R. B., Qin, S. X., and Hyman, B. T. (2000). Expression of the chemokine receptor CXCR3 on neurons and the elevated expression of its ligand IP-10 in reactive astrocytes: in vitro ERK1/2 activation and role in Alzheimer's disease. J. Neuroimmunol. 108, 227-235. doi: 10.1016/ S0165-5728(00)00285-X

Zaheer, S., Thangavel, R., Wu, Y., Khan, M. M., Kempuraj, D., and Zaheer, A. (2013). Enhanced expression of glia maturation factor correlates with glial activation in the brain of triple transgenic Alzheimer's disease mice. Neurochem. Res. 38, 218-225. doi: 10.1007/s11064-012-0913-Z

Zhang, R., Miller, R. G., Madison, C., Jin, X., Honrada, R., Harris, W., et al. (2013). Systemic immune system alterations in early stages of Alzheimer's disease. J. Neuroimmunol. 256, 38-42. doi: 10.1016/j.jneuroim.2013.01.002

Zhou, M., Greenhill, S., Huang, S., Silva, T. K., Sano, Y., Wu, S., et al. (2016). CCR5 is a suppressor for cortical plasticity and hippocampal learning and memory. Elife 5, e20985. doi: 10.7554/eLife.20985

Zinni, M., Zuena, A. R., Marconi, V., Petrella, C., Fusco, I., Giuli, C., et al. (2017). Maternal exposure to low levels of corticosterone during lactation protects adult rat progeny against TNBS-induced colitis: a study on GR-mediated antiinflammatory effect and prokineticin system. PLoS One 12, e0173484. doi: 10.1371/journal.pone.0173484

Zou, Y. R., Kottmann, A. H., Kuroda, M., Taniuchi, I., and Littman, D. R. (1998). Function of the chemokine receptor CXCR4 in haematopoiesis and in cerebellar development. Nature 393, 595-599. doi: 10.1038/31269

Conflict of Interest Statement: The authors declare that the research was conducted in the absence of any commercial or financial relationships that could be construed as a potential conflict of interest.

Copyright (c) 2019 Zuena, Casolini, Lattanzi and Maftei. This is an open-access article distributed under the terms of the Creative Commons Attribution License (CC $B Y)$. The use, distribution or reproduction in other forums is permitted, provided the original author(s) and the copyright owner(s) are credited and that the original publication in this journal is cited, in accordance with accepted academic practice. No use, distribution or reproduction is permitted which does not comply with these terms. 